\title{
Fuchs Endothelial Corneal Dystrophy
}

\author{
Hussain Elhalis, MD $1,3,{ }^{*}$, Behrooz Azizi, $\mathbf{M D}^{1,3}{ }^{,}{ }^{*}$, and Ula V. Jurkunas, $\mathbf{M D}^{1,2,3}$ \\ ${ }^{1}$ Schepens Eye Research Institute, Harvard Medical School, Boston, MA \\ 2 Massachusetts Eye \& Ear Infirmary, Harvard Medical School, Boston, MA \\ ${ }^{3}$ Department of Ophthalmology, Harvard Medical School, Boston, MA
}

\begin{abstract}
Fuchs endothelial corneal dystrophy (FECD) is characterized by progressive loss of corneal endothelial cells, thickening of Descement's membrane and deposition of extracellular matrix in the form of guttae. When the number of endothelial cells becomes critically low, the cornea swells and causes loss of vision. The clinical course of FECD usually spans 10-20 years. Corneal transplantation is currently the only modality used to restore vision. Over the last several decades genetic studies have detected several genes, as well as areas of chromosomal loci associated with the disease. Proteomic studies have given rise to several hypotheses regarding the pathogenesis of FECD. This review expands upon the recent findings from proteomic and genetic studies and builds upon recent advances in understanding the causes of this common corneal disorder.
\end{abstract}

\section{Keywords}

Fuchs endothelial corneal dystrophy; corneal endothelium; proteomics; genetics; pathophysiology; oxidative stress; apoptosis; antioxidants; collagen VIII

\section{INTRODUCTION}

The purpose of this article is to review and outline recent findings on Fuchs endothelial corneal dystrophy (FECD) with a focus on the genetics and molecular mechanisms. In the last decade, extensive work has been done to pinpoint the pathogenesis of FECD, including the classification of FECD subtypes, discovery of novel mutations, mapping of chromosomal loci, and investigation of several hypotheses regarding the etiology of the disease. Proteomic and genomic analyses have further illuminated the molecular mechanisms altered in FECD. These directions of research provide a new foundation for elucidating the primary etiology of FECD and will be summarized in this review.

\section{METHODS}

Data identification was made through extensive, computer-assisted PubMed searchs for English-language articles and then cross-checking their references. Articles providing recent findings on the pathophysiology, genetics, and proteomics of FECD were included in this review. Data selection included published original works on FECD and information

Corresponding Author: Ula V. Jurkunas, Schepens Eye Research Institute, 20 Staniford Street, Boston, MA 02114; Tel:

617-912-0245; Fax: 617-912-0101; Ula.jurkunas@ schepens.harvard.edu.

Authors contributed equally.

${ }^{1}$ R01 EY020581 (UVJ); K12 EY016335 (UVJ).

2 The authors have no proprietary or commercial interests in any concept or product discussed in this article. 
contained in several review articles on the disease; articles through June 2009 were included.

\section{WHAT WE KNOW}

\section{A. Overview}

Corneal endothelium is located in the inner portion of the cornea and has a key function of keeping the cornea transparent. Corneal endothelium $(\mathbf{C E})$ forms a monolayer of hexagonal cells that is attached to its basement membrane, called Descemet's membrane (DM) and is in direct contact with the aqueous humor. One of the major functions of $\mathrm{CE}$ is to retain corneal clarity by the endothelial barrier and pump functions. Ernst Fuchs described a bilateral corneal dystrophy in 1902, later published in 1910,1 now known as FECD. The primary defect is thought to be in the functioning of the endothelial cell layer, as confirmed by ultrastructural studies. ${ }^{2}$ FECD is characterized by the morphological changes of the hexagonal mosaic, accelerated loss of endothelial cells, and a concomitant increase in the extracellular matrix deposition at the level of DM. As a result, the endothelial layer is eventually no longer able to support corneal deturgescence (a state in which corneal stroma is maintained relatively dehydrated), leading to corneal edema and decreased in visual acuity (Figure 1). These findings usually become clinically evident in the fourth and fifth decades of life. ${ }^{3-5}$ Initially, the patient notices blurred vision, then symptoms progress as the disease progresses through its stages_often ending in blindness.

\section{B. Clinical Staging}

Several staging systems for FECD have been utilized in the past; one of the commonly used systems describes the disease progression in four stages. 6,7

Stage 1-In this stage, corneal biomicroscopy reveals corneal guttae, which are moundshaped excrescences growing from the DM considered a hallmark of FECD. The guttae usually start in the central cornea and spread towards the periphery. In this stage, guttae are usually central and non-confluent. The patients are asymptomatic at this stage.

Stage 2-In this stage, corneal guttae start to coalesce and further spread towards the peripheral cornea. The guttae grow along the DM and are accompanied by endothelial cell thinning, enlargement, and loss of hexagonal shape. ${ }^{8,}{ }^{9}$ The number of guttae is inversely proportional to the endothelial cell density, as the coalescence of guttae is accompanied by continual loss of endothelial cells. The patients begin to experience a painless decrease in vision and glare symptoms due to increasing edema of stromal layers.

Stage 3-In this stage, stromal edema further progresses towards the epithelial layer and causes formation of epithelial and subepithelial bullae. ${ }^{6}$ The rupture of these bullae causes episodes of pain ${ }^{10,11}$ and places a patient at a higher risk of infection.

Stage 4-In this stage, the cornea becomes densely opaque and vascularized. ${ }^{6,7}$ There is subepithelial fibrous tissue deposition in response to prolonged and chronic edema. Visual acuity is severely compromised at this stage, but the pain usually subsides.

Interestingly, a non-guttae form of FECD has also been described ${ }^{12-14}$ However, central guttae can be found in the elderly without the development of corneal edema or decrease in visual acuity and this, therefore, is not classified as FECD. ${ }^{15}$ Corneal guttae found only at the periphery can be normal findings in the aging population and are called Hassal-Henle bodies and never lead to corneal edema. $6,9,15,16$ Corneal guttae can also form secondary to 
trauma, ${ }^{7}$ toxins,,${ }^{17}$ or infections. ${ }^{18-21}$ Thus, FECD diagnosis cannot be made based solely on the presence of corneal guttae; corneal edema must also be present.

\section{New IC3D Classification and Inheritance}

New IC3D classification system for corneal dystrophies consists of four categories that reflect the known genetic and pathologic evidence for a given dystrophy. ${ }^{22}$ FECD falls into categories $1-3$ by the IC3D classification. Category 4 is reserved for suspected new corneal dystrophies and does not fit the profile of FECD. Some of the inherited cases of FECD are autosomal dominant. ${ }^{23}$

Category 1 indicates a well-defined corneal dystrophy in which the gene has been identified and a specific mutation is known. Early-onset FECD, mapped to COL8A2 (FECD C1), fits into this category. Early-onset FECD usually begins in the first decade and becomes clinically detectable in the $2^{\text {nd }}$ and $3^{\text {rd }}$ decades.

Category 2 indicates a well-defined corneal dystrophy that has been mapped to 1 or more specific chromosomal loci, but the gene(s) remains to be identified. Familial FECD is included in this category (FECD C2) where multiple chromosomal loci have been mapped. Familial FECD is described in the literature as a primarily autosomal dominant condition. ${ }^{23-} 25$

Category 3 indicates a well-defined corneal dystrophy in which the chromosomal locus has not been identified and includes a large percentage of familial FECD cases.

Note (1) the IC3D classification applies only to hereditary cases of FECD and does not apply if no evidence of inheritance is present. (2) Some authors argue that the majority of FECD cases are more like degeneration than a dystrophy due to FECD's late onset, a lack of family history of the disease, and occasional asymmetric pattern, commonly associated with degeneration. ${ }^{6,8}$

\section{Prevalence}

FECD can be divided into early-onset (manifesting in the $3^{\text {rd }}$ decade of life) and late-onset (manifesting in the $5^{\text {th }}$ decade of life, on average). Both early- and late-onset forms have female predominance at a ratio of 2.5-3:1. $3,12,23-26$ Although some authors do not report a racial disparity, ${ }^{15}$ Santo et al. ${ }^{27}$ stated that FECD is extremely rare in Japan. It is also uncommon in Saudi Arabia, and in the Chinese of Singapore. ${ }^{28}$ In the USA, the prevalence is approximately $4 \%$ of the population over the age of $40 .{ }^{26}$ The difficulties encountered by many investigators when performing the prevalence analysis on FECD are the late onset of the disease and scarcity of full pedigrees of living patients with FECD for analysis. The indolent course of the disease allows many FECD patients to remain undiagnosed and potentially decreases the statistical power of research results. This contributes to the differences in reported penetrance and sex ratios. Magovern et al. ${ }^{25}$ reported equal female to male ratios with $100 \%$ penetrance in 16 affected patients from four generations, while Rosenblum et al. ${ }^{24}$ reported a female to male ratio of 7:1 with variable expressivity and increased severity in the female population. Their results were pooled from 102 patients in 25 families.

\section{E. Associated Conditions}

There is conflicting evidence regarding whether there is an association with open angle glaucoma and FECD. ${ }^{29-31}$ Buxton et al. ${ }^{30}$ found that the drainage of aqueous outflow was decreased in eyes of FECD patients as compared to normal controls. The study concluded that the trabecular meshwork might be involved in the disease process. Similarly, studies 
have shown that the intraocular pressure of FECD patients is significantly higher than that of normal subjects. In addition, there may be an underestimation error due to the significantly increased central corneal thickness found in FECD patients. ${ }^{32}$ In contrast, other studies found no impairment of aqueous outflow ${ }^{31}$ and no association between open-angle glaucoma and FECD. ${ }^{25}$

FECD has been associated with a higher incidence of keratoconus $33^{-} 35$, age-related macular degeneration36, and cardiovascular disease. ${ }^{37}$ In a report by Olsen, increased cardiovascular disease risk in the 27 examined FECD patients (44\% vs $11 \%$ ) was hypothesized to be due to a common endothelial factor abnormality, ${ }^{37}$ although it is known that corneal endothelial cell lineage is distinct from that of vascular endothelium. It is possible that such reported disease associations are due to a more complex interplay of patients' susceptibility to environmental factors that leads to premature degenerative changes, not only in CE but also in retinal and cardiovascular tissues.

\section{F. Barrier or Pump Dysfunction}

Endothelial cells are selective barriers allowing leakage of solutes and nutrients from the aqueous humor to the avascular cornea. On the other hand, Na-K ATPase pumps, located in basolateral CE membranes, actively transport the fluid out of the cornea and back to the aqueous humor to maintain the cornea in a relative state of deturgescence. Dysfunction of either the barrier or the pumps result in corneal edema as seen in FECD.

Burns et al. ${ }^{38}$ studied FECD patients with increased central corneal thickness but without epithelial edema The major finding was increased permeability rate in FECD CE, without a difference in a pump rate, suggesting that the earliest defect in FECD is the breakdown of the barrier function of the endothelial monolayer, which causes increased flow of fluid into the cornea, without sufficient compensatory increase in pump function. However, in a later study, Wilson et al. ${ }^{39}$ found no difference in the permeability rate of a larger sample of FECD patients when compared to the normal volunteers, suggesting that the pump rate is reduced and the barrier function is intact in FECD. The disparity between the two studies may reflect the fact that pump and barrier functionsmight be affected differently in various stages of the disease.

Several other studies have suggested that altered pump dysfunction plays a key role in FECD. Bergmanson et al. ${ }^{40}$ examined histopathologic sections of FECD corneas and detected that aberrant deposition of extracellular matrix caused stretching and thinning of $\mathrm{CE}$ cells positioned on top of guttae. The cell bodies were displaced peripheral to the stem of the guttae, while over the apices of the guttae, the cell membranes were intact. Since there was no space for organelles over these stretched areas, the authors argued it is unlikely that CE cell pump function is intact over those areas. Similarly, other studies on Na-K ATPase pump activity in corneal edema, such as that seen in FECD and pseudophakic bullous keratopathy (PBK), showed that pump density is markedly decreased in the end-stage disease. ${ }^{41}$ In summary, loss of endothelial cells leads to the breakdown of barrier function. Even though the remaining endothelial cells attempt to compensate by increasing the pump function, the continued loss of cells leads to the critically low number of the pump sites and inability of the cornea to maintain the deturgescent state.

\section{G. Histopathology}

Since the endothelial cells are arrested in the post-mitotic state and exhibit minimal ability to divide in vivo, endothelial cell loss seen in FECD is permanent. Along with reduced endothelial cell count, there are marked morphological changes in the corneal endothelial cell mosaic that are clinically visible with specular microscopy (Figure 2). The variability in 
human corneal endothelial cell (HCEC) size is denoted as polymegathism, and variability in endothelial cell shape-pleomorphism. In Figure 2, dark oval and round areas in between the hyperreflective malformed endothelial cells represent the guttae.

Even though most researchers agree that the primary abnormality in FECD lies in the endothelium, degenerative changes have been detected in all layers of an FECD-affected cornea. Ultrastructural studies of FECD suggest that the primary disease is in the corneal endothelium, and that the accompanying changes in Descemet's membrane, stroma and epithelium are secondary to that the pathology. $2,3,6$ Corneal endothelium of FECD patients has been shown to exhibit prominent rough endoplasmic reticulum, lysosomes, and increased presence of coated vesicles in the cytoplasm. Some endothelial cells showed prominent cytoplasmic processes that led to the hypothesis of endothelial cell transformation into fibroblasts in FECD. ${ }^{2,}{ }^{3,6}$ In addition, prominent melanosomes have been detected within the endothelial cells along with swollen mitochondria, dilated rough endoplasmic reticulum and widened intercellular spaces. ${ }^{42}$ It is important to note, that electron microscopic studies of FECD corneas detected degeneration of all layers, including stromal keratocytes, epithelium and stromal collagen fibrils.

During normal development, thin and short filaments are deposited perpendicular to the plane of the DM and are detected as early as 4 months of gestation. Prenatal DM is lamellar and forms banded layers that can be discerned at about 8 months of gestation. ${ }^{43}$, 44 This banded layer posterior to the stroma is termed the anterior banded layer (ABL). This process changes at birth when the deposition is no longer banded, thus forming a discrete second layer of the DM; this new non-banded, nonlamellar deposit is called the posterior nonbanded layer (PNBL). ${ }^{7,}{ }^{45}$ By gradually increasing in thickness by approximately $0.1 \mu \mathrm{m} /$ year, the normal PNBL reaches a thickness of approximately $10 \mu \mathrm{m}$, at 80 years of age. ${ }^{46}$

Histological and ultrastructural comparison of normal, early-onset FECD (specifically, specimens taken from patients with a L450W COL8A2 mutation), and commonly seen lateonset FECD corneas show distinct histological patterns. ${ }^{46,}{ }^{47}$ In the normal corneas, $\alpha 1$ and $\alpha 2$ components of collagen VIII are evenly distributed in the ABL of the DM. However, in early- and late-onset FECD, $\alpha 1$ and $\alpha 2$ fibers are not regularly distributed.

In contrast to late-onset FECD, early-onset FECD has markedly thickened ABL ( $10 \mu \mathrm{m}$ vs $3.1 \mu \mathrm{m}){ }^{44}, 45$ Since $\mathrm{ABL}$ is presumed to develop during early fetal life, changes in ABL, as seen in early-onset FECD, may represent pathological processes that start in utero and continue to develop into adulthood.2, 46 Another characteristic histological finding of earlyonset FECD is formation of a new layer, called posterior internal collagenous layer (ICL), which contains a dense fibrous component and widely spaced collagen arranged in disorganized fashion. The posterior-most part of DM in early-onset FECD is comprised of a posterior striated layer (PSL), which contains collagen IV, fibronectin, and laminin, similar to basal layers of other tissues. ${ }^{46}$

In late-onset FECD, the characteristic thickening of the DM is due to the deposition of an additional, PBL, posterior to the PNBL. ${ }^{2,} 7$ The PBL is markedly thickened, ranging from 10 to $20 \mu \mathrm{m},{ }^{2}$ and contains abnormally deposited collagen and the classic posterior excrescences, guttae. ${ }^{46}$ Some late-onset FECD patients have even shown a posterior fibrous layer (PFL) between the PBL and the endothelium. ${ }^{2},{ }^{48-50}$ In late-onset FECD DM, the $\mathrm{ABL}$ is of near normal thickness, and the major abnormalities are present in the postnatal layers. PNBL is thinner than normal or even absent in some cases. ${ }^{2,} 46$ 


\section{GENETICS}

\section{A. COL8A2 Gene}

Genetic Mutations-A major constituent of normal DM is type VIII collagen, which is secreted by corneal endothelium and assembled into a hexagonal lattice structure ${ }^{51}$ through the interaction of collagen VIII $\alpha 1$ and $\alpha 2$ polypeptides. Normally, collagen VIII is an especially prominent constituent of ABL of the DM. ${ }^{52,53}$ One of the first genetic defects identified in FECD was mutations in COL8A2 gene, which are associated with early-onset FECD (Table 1)

Biswas et al. ${ }^{54}$ demonstrated linkage to chromosome 1p34.3-p32 in three-generations of a family with a highly penetrant, early-onset form of FECD. Among the affected individuals in the family, diagnosis of FECD was made between the ages of 21-48 years; almost half of the members required corneal transplantation. After sequencing the gene in the affected patients, a Gln455Lys (Q455K) missense mutation in COL8A2 gene, which encodes the $\alpha 2$ chain of type VIII collagen, was identified. The Gln455Lys substitution involves replacement of highly conserved glutamine with negatively charged lysine that may alter the tertiary structure of the protein. In addition, another early-onset FECD family and one family with posterior polymorphous dystrophy (PPCD) demonstrated the same point mutation in the COL8A2 gene. Since collagen VIII is a major component of DM and is aberrantly overproduced in FECD, the mutation provided an indication of a possible role for collagen VIII in influencing terminal differentiation of corneal endothelial cells and causing molecular dysfunction of endothelial extracellular matrix in FECD.

Similarly, Gottsch et al. ${ }^{55}$ analyzed one multigenerational family with early-onset FECD that had 17 affected and 5 unaffected family members. A genome-wide linkage analysis demonstrated a novel point mutation in the COL8A2 gene with Leu450Trp (L450W) substitution. Patients affected by the mutation had, on average, 40 years' earlier onset of severe grade (grade 3 or greater) than late-onset disease. Interestingly, there was 1:1 female to male ratio, which did not show female predominance as seen in late-onset FECD. In addition, the clinical phenotype of the disease was different; confocal specular microscopy detected a single, low elevation gutta associated with individual cells in early-onset disease as opposed to sharply raised guttae with high elevation and areas of coalescence in the lateonset FECD. Interestingly, the rate of disease progression was similar between early L450W mutation and late-onset subtypes of FECD, which spans about 25 years.

In addition, Mok et al. ${ }^{56}$ identified a Q455V mutation in exon 2 of COL8A2 in Korean patients with FECD. The mutation was present in 12 patients from 6 pedigrees with a family history of FECD, and in 2 out of 9 unrelated cases. The appearance of guttae was similar to that seen in patients with L450W and Q455K mutations.

Despite identification of COL8A2 amino acid sequence variants in early-onset FECD, no association between these gene mutations and the more common, late-onset variants of FECD has been made. in more common, late-onset variants of FECD. Kobayashi et al. ${ }^{57}$ did not detect COL8A2 mutations in Japanese patients with FECD. Similarly, Aldave et al. ${ }^{58} \mathrm{did}$ not detect an association between COL8A1 and COL8A2 mutations with late-onset variants of FECD.

Collagen VIII Deficient Mice-To obtain better insight into the role of collagen VIII in the development of corneal dystrophies, ${ }^{54}$ Hopfer et al. generated mice deficient in $\alpha 1$ and $\alpha 2$ chains of collagen VIII.59 Such disruption of type VIII collagen did not result in histological abnormalities in most organs, and did not affect mouse fertility, development, or life span.59 The cornea, on the other hand, exhibited keratoglobus-like protrusions with 
diffuse thinning of corneal stroma. DM was markedly thinned and lacked ABL, as expected, since collage VIII is a key component of ABL.52, 53 No guttae were observed, and there was no evidence of corneal opacification. HCECs were reduced in number and showed morphological changes of increased polymorphism and polymegathism. The authors suggested that during embryologic development, collagen VIII is necessary to guide corneal mesenchymal cell migration and proliferation, thus, absence of such layer, impairs corneal development and results in thin corneas with low endothelial cell numbers. In late-onset FECD, the pathogenesis of the disease centers on heightened collagen VIII secretion in later years of life (as opposed to embryogenesis), which in turn leads to abnormal DM thickening and endothelial cell apoptosis. These findings suggest that pathogenic mechanisms are most likely quite different between collagen VIII-deficient mice and collagen VIII deposition in FECD patients. Nevertheless, insights into collagen VIII interaction with endothelial cells might provide a better understanding of aberrant extracellular matrix deposition in FECD.

\section{B. SLC4A11 Gene}

Genetic Defect in FECD—Vithana et al. ${ }^{28}$ showed that heterozygous mutation in SLC4A11 is associated with late-onset FECD in 89 unrelated patients of Chinese and Indian decent. Only 10 out of the 89 patients had a family history of FECD, thus, the majority of cases were classified as sporadic. In the study, 4 novel heterozygous $S L C 4 A 11$ gene mutations ( 3 missense mutations and 1 deletion mutation) were identified in the FECD cohort that were absent in more than 350 ethnically matched controls. The manifestation of the FECD phenotype in individuals with heterozygous SLC4A11 mutations suggests that FECD will be inherited as a dominant trait. They concluded that approximately $5 \%$ of FECD in Chinese patients and 4\% of FECD in Indian patients can be attributed to mutations in the SLC4A11 gene.

The SLC4A11 gene encodes NaBC1, which is a member of the solute carrier 4 family that function as bicarbonate transporters and, specifically, as sodium borate cotransporters. ${ }^{60,} 61$ Previously, mutations in SLC4A11 have been shown to cause congenital hereditary endothelial dystrophy (CHED). ${ }^{62}$ Vithana et al. ${ }^{28}$ showed that missense mutations in the SLC4A11 gene lead to aberrant glycosylation and decreased targeting of the SLC4A11 protein to the cell surface, resulting in insufficient SLC4A11 protein levels at the corneal endothelial cell surface.

SLC4A11 Knockout Mouse-In order to investigate the role of $\mathrm{NaBC} 1$ on mammalian sensorineural system, a $S L C 4 A 11$ knockout mouse was developed. ${ }^{63}$ Since mutations in the SLC4A11 gene are known to cause Harboyan syndrome, which manifests in hearing loss, the animals with deletion of the SLC4AII gene had significant abnormalities in the audiovestibular system. On the other hand, no significant differences in endothelial cell size, shape, and density were observed between age-matched SLC4A11 - /- and SLC4A11 +/+ mice at 3,5, and 10 months of age. Also, the DM did not present with any abnormalities in the knockout mice. The primary phenotypic change seen in the cornea was an increase in absolute height of corneal basal epithelial cells. The central corneal and epithelial layer thicknesses remained the same, but the ratio of the basal layer to total epithelial thickness was greater in the knockout mice. Such difference in corneal phenotype between humans and mice deficient in $\mathrm{NaBC} 1$ may be due to the differences in the role of $\mathrm{NaBC} 1$ in corneal anatomy, physiology, development, and gene-environment interactions between the species. Nevertheless, the insights into why mouse corneas did not exhibit dystrophic phenotype could provide a better understanding of the molecular basis of FECD as well as conditions such as CHED. 


\section{Chromosomal Loci}

Until 2005, the only reported genetic mutations involved in FECD were found in the earlyonset subtype of the disease. ${ }^{54,55}$ The first genetic locus for the more common late-onset FECD was mapped by Sundin et al. ${ }^{64}$ to chromosome 13, called Fuchs corneal dystrophy locus 1 (FCD1). Subsequently, two other loci, FCD2 and FCD3, were mapped to chromosomes $18,{ }^{65}$ and $5,{ }^{66}$ respectively. In addition, Afshari et al. ${ }^{67}$ provided evidence for potential linkage at chromosomes $1,7,15,17$ and $\mathrm{X}$ by genome-wide linkage analysis. Some of these studies suggested a complex inheritance pattern in familial FECD,${ }^{67}$ while others pointed to the autosomal dominant pattern. 65,66

The first genetic locus for late-onset FECD (called, FCD1) that was mapped to the 13pTel-13q12.13 interval followed a typical autosomal dominant inheritance pattern. ${ }^{64}$ The cohort consisted of a 4-generation pedigree of 20 affected individuals of European descent. Although the reported ratio of affected to unaffected was 1:1, the ascertainment bias was thought to play a role. Despite identification of the genetic locus, the candidate genes were difficult to pinpoint. 13p12 is known as the RNR1 nucleolus organizer, composed largely of tandem repeats of the $5 \mathrm{~s}, 18 \mathrm{~s}$, and $28 \mathrm{~s}$ ribosomal genes.64 Genes within the sequenced $\mathrm{q}$ arm of 13q12.11-13q12.13 interval were investigated, but none appeared to be major components of the cornea or the DM. Possible difficulties in identifying the FCD1 mutation are its dominant nature and its mild, late-onset phenotype. In addition, the mutation could be in a noncoding promoter region that causes a modest change in mRNA levels. Another possibility is that the FCD1 mutation could be a gene deletion, that is not detectable by conventional exon screening.64

A second locus for late-onset FECD (FCD2) was mapped to 18q21.2-q21.32. ${ }^{65}$ This was the result of a genetic-linkage analysis of 3 large families that showed autosomal dominant inheritance of late-onset FECD. Both penetrance (90\%) and phenocopy (22\%) rates in this study population were higher than in the general population and could be explained by ascertainment bias. Although this region of chromosome 18 (18q21) has been better characterized than the FCD1 locus and 28 potential genes are now under investigation, the specific mutation causing the FCD2 phenotype remains unknown.

More recently, the FCD3 locus was identified in a single large family ${ }^{66}$ None of the known FCD1, FCD2, and COL8A2 loci were detected in any of the members of this family, and a genome-wide scan produced linkage at the 5q33.1-q35.2 interval. The significance of the genes spanning this interval is uncertain and the identification of this third locus further supports heterogeneity for late-onset FECD. FCD3 is generally less severe in terms of age of onset and rate of progression compared to FCD1 and FCD2 loci.

In a study by Afshari et al. ${ }^{67}$, the first genomic-wide linkage analysis of FECD was performed by analyzing both multigenerational and complex families, unlike the other studies previously discussed. The examination of 22 families identified potential linkage regions on chromosomes $1,7,15,17$ and $\mathrm{X}$. Interestingly, the linkage peak on chromosome 1 was only $3 \mathrm{Mb}$ away from the COL8A2 gene; however, screening of this patient population for the COL8A2 mutations L450W and Q455K was negative. The findings on chromosomes 7,15 , and $\mathrm{X}$ were derived from both small and large family aggregates and supported the notion that FECD can be inherited both as autosomal dominant and in a complex fashion. ${ }^{67}$ 


\section{PATHOPHYSIOLOGY}

\section{A. Apoptosis}

Apoptosis is a recognized mechanism of cell death involved in multiple disease processes in the body. ${ }^{68-72}$ Similarly, in FECD, apoptosis has been shown to have a major role in corneal endothelial cell death.

Borderie et al. ${ }^{73}$ were the first to detect apoptosis in endothelial cells by using nucleus labeling, transmission electron microscopy (TEM), and TdT-dUTP terminal nick-end labeling (TUNEL) assays on FECD-affected corneas. Morphological assessment using an epifluorescence microscope after nucleus labeling by Hoeschst 33258 showed significantly more apoptotic endothelial cells in FECD specimens compared to normal; apoptotic rate was $2.65 \%$ in the FECD group and $0.23 \%$ in the control group. By using a different apoptosis assay, the TUNEL assay, 42 out of 47 FECD endothelial specimens were shown to be positive for apoptosis while apoptosis was absent in control corneal buttons. Use of TEM, however, did not result in any conclusive evidence of apoptosis, which was consistent with previous studies. ${ }^{2}, 6,12,48,74$ A possible explanation for such discrepancy in the results was that only a small percentage of endothelial cells were undergoing apoptosis at the time of analysis, rendering it difficult to detect an apoptotic endothelial cell in a cross section. In addition, apoptosis was detected in the basal epithelial cell layer in FECD by all 3 methods. 73

Similarly, Li et al. ${ }^{75}$ identified apoptosis in endothelium, stroma, and epithelium of FECD corneas, using TUNEL assay. Finding apoptotic cell death in keratocytes in FECD but not in other pathologic specimens sparked a hypothesis that stromal cells have a potential involvement in endothelial degeneration seen in FECD. The authors found a statistically significant difference in the production of Bax (pro-apoptotic protein) in the stroma but not in the endothelium of FECD corneas. They also showed an increased level of Bax (proapoptotic protein) but a decreased level of Bcl-2 (anti-apoptotic protein) in FECD keratocytes, following the exposure to camptothecin (apoptotic inducer) ${ }^{75}$ It is arguable whether findings of apoptosis in epithelial and stromal cell layers in FECD represent a pathogenic mechanism or are secondary to degeneration of endothelium and resultant corneal edema. Studies that show apoptotic cell marker alteration in corneal epithelial cells and not endothelium in FECD76 might suggest that endothelium is much more difficult to stain and study with immunohistological stains in histological cross sections.

\section{B. Gene Expression and Proteomic Analyses}

Proteomic and gene expression analyses may aid in clarifying the underlying mechanism and etiology of FECD. Several gene expression profiles have been investigated and found to be different in FECD corneas as compared to normal corneas. Based on theses analyses, there is mounting evidence that interaction between genetic and environmental factors contribute to the complex alterations in the proteome and genome of the diseased endothelial cells, and that addressing such interactions will enable a better characterization of the pathogenic mechanisms involved.

Some of the initial studies used serial analysis of gene expression (SAGE) to compare gene expression profiles between corneal endothelium taken from FECD and normal patients. The analysis revealed an alteration in expression of genes regulating cellular energy metabolism, pump functions, and apoptotic and antioxidant cell defense. The downregulated transcripts exceeded the upregulated ones and mitochondrial transcripts accounted for the majority of these downregulated genes. These data were consistent with previous studies that showed decreased mitochondrial and pump site densities in FECD ${ }^{41,} 77$ and indicates a potential decrease in mitochondrial delivery of an adequate energy source. In addition, a 
comparison between normal and FECD gene libraries revealed a significant decrease in the expression of bicarbonate transporter-related protein-1. This finding is potentially related to the genetic deficiencies in the $S L C 4 A 11$ gene, although that connection has not been fully investigated to date.

To test the hypothesis that there is differential dysregulation of protein synthesis and/or secretion in FECD-affected cells, proteomic analysis was performed to identify differentially produced proteins in FECD as compared to normal endothelium. ${ }^{78-80}$ The proteins were extracted from native FECD and age-matched normal endothelium-Descemet's membrane complex, and 2-D gel analysis was performed. The proteins were identified by proteomic analysis. Several differences were detected prompting further investigations to better characterize the pathogenic mechanisms in FECD.

Clusterin and Transforming Growth Factor- $\beta$-Induced Protein-Studies of comparing proteins from human corneal endothelial cell-Descemet's membrane complexes identified marked overexpression of the pro-aggregative, chaperone-like protein, called clusterin $(\mathbf{C L U})$ in FECD samples ${ }^{79}$. Generally, CLU is overexpressed in many tissues undergoing stress, including those in cancers and neurodegenerative disorders, and aids in cell survival under cytotoxic conditions ${ }^{81-83}$. Because of its cytoprotective and antiapoptotic properties, secretory CLU (sCLU) acts as a pro-survival factor for most cells ${ }^{84}$, 85 . Another form of CLU, nuclear CLU (nCLU), located in the nucleus promotes apoptosis in stressed cells, acting as a proapoptotic protein ${ }^{86} 88$. nCLU is the uncleaved and nonglycosylated form of CLU that is targeted for the nucleus. Expression of pre-sCLU and nCLU was found to be increased significantly in FECD samples compared to normal decade matched controls. Comparatively, CLU mRNA expression in other edematous pathologies like PBK HCECDM was lower than in normal controls, indicating that this phenomenon is more specific to FECD corneas. Immunocytochemistry studies revealed rosette-type clustering of endothelial cells around guttae and increased intracellular staining of CLU intracellularly as well as in the centers of the guttae. This was thought to represent cellular debris in guttae ${ }^{79}$. Endothelial cell nuclei were also clustered around the guttae possibly owing to the aggregative and possibly protective function of $\mathrm{CLU}^{89}, 90$.

Further analysis of proteomic composition of guttae, revealed that transforming growth factor- $\beta$-induced protein (TGFBIp) plays is a key role in guttae formation.78 TGFßIp is an extracellular matrix adhesion molecule that interacts with collagens, integrins and fibronectins $91^{-95}$. Investigation of proteolytic processing of TGFßIp in normal human endothelium revealed age-related posttranslational modification of varying forms of TGF 3 Ip. The findings were consistent with gradual thickening of DM throughout lifetime and consistent with increasing accumulation of TGFßIp which is known to have physiologic interaction with collagens. In addition, 2-D gel analysis showed increased production of TGFBIp in FECD HCEC-DM complexes compared to control subjects ${ }^{79}$. Comparing the levels of proteolytically modified forms between normal and FECD endothelium, a five-fold increase in the $68 \mathrm{kDa}$ band (full-size protein), and an increase in the $58 \mathrm{kDa}$ and $39 \mathrm{kDa}$ bands in FECD endothelium was detected. Real-time PCR revealed an upregulation of $T G F \beta I$ mRNA levels in FECD endothelium compared to controls showing that the difference stems from the gene transcription level. Finally, indirect immunofluorescence analysis revealed colocalization of CLU and TGF $\beta$ Ip in FECD endothelium with markedly increased intensity at the centers of guttae (Fig. 4A). TGF $\beta$ Ip showed significant staining at the level of the DM, with the most intense staining tending toward the lower portions of the guttae, while CLU localized above TGFßIp. The schematic representation of guttae formation in FECD (Fig. 4B) depicts gradual thickening of the DM by the accumulation of TGF $\beta I p ;$ CLU overexpreesion and secretion by stressed cells is seen in the 'youngest' portions of guttae. (Fig. 4B). 
Even though the exact significance of the CLU and TGF $\beta$ Ip interaction is unclear, the overproduction of these proteins might be due to a stress-response during which cells attempt to aggregate via cell-cell and cell-substratum interactions and counteract proapoptotic stimuli.

Peroxiredoxins and Antioxidant Defense-Proteomic analysis of normal corneal endothelium has identified the presence of a novel class of antioxidants, peroxiredoxins (PRDXs), that function by removing cellular hydrogen peroxide and inhibiting apoptosis in response to reactive oxygen species (ROS). Two-dimensional gel and western blot analyses comparing FECD and age-matched corneal donors showed significantly decreased levels of PRDX-2, and -6 isoforms in FECD endothelial cells compared to normal samples. ${ }^{80}$ PRDX-2 is particularly important in anti-apoptotic defense by inhibiting release of cytochrome $\mathrm{c}$ from mitochondria and regulating gene transcription via its inhibiting effects on hydrogen peroxide-induced activation of NF-kB. ${ }^{96-98}$ PRDX-3 and -5 were not detected in FECD endothelial cell samples as compared to normal controls. A similar finding of decreased PRDX-3 expression has been shown in other diseases where ROS induced apoptosis is implicated; Alzheimer's disease and Down's syndrome. ${ }^{99}, 100$ The primary site of PRDX-3 is in the mitochondria for antioxidant defense in the respiratory chain. ${ }^{96}$ PRDX-5 has been found in the mitochondria, peroxisomes, and nucleus for anti-apoptotic function and ROS defense. ${ }^{101-103}$

There is mounting evidence in the literature that chronic oxidative stress contributes to cellular and molecular damage in genetically and/or environmentally susceptible human corneal endothelial cells, which in turn leads to pathological findings of FECD. Initial study by Buddi et al. ${ }^{104}$ used antibodies against lipid peroxidation and other ROS byproducts and identified oxidative damage in FECD corneas. Wang et al. ${ }^{105}$ showed increased levels of advanced glycation end products (AGE) and their receptors (RAGE) in the DM and corneal endothelium of FECD patient samples. The location of AGE deposits was in the anterior segment of the DM, which is the oldest portion of DM with the most prolonged exposure to oxidative stress; such findings provided important evidence that deleterious effects of oxidative stress may occur very early and continue throughout life in the corneal endothelium of FECD patients ${ }^{105}$.

In addition to decreased antioxidant defense, studies have detected distinct oxidative DNA damage, as measured by oxidatively modified guanosine base (8-OHdG), in FECD-affected corneal endothelium. Oxidative injury colocalized to the mitochondrial DNA, indicating that mitochondria are the primary targets of oxidative damage in $\mathrm{FECD}^{106}$. The mitochondrial respiratory chain is a major internal source of ROS production; thus, mitochondria accumulate oxidative damage more rapidly than the rest of the cell. ${ }^{107}$ Mitochondrial DNA damage is known to cause dysfunctional mitochondrial protein synthesis, loss of integrity of inner mitochondrial membrane potential, and apoptotic cell death. Interestingly, older studies by Tuberville et a ${ }^{77}$ showed decreased numbers of mitochondria and a decline in cytochrome oxidase activity in the mitochondria of edematous FECD corneas. The findings of decreased antioxidant defense and oxidative tissue damage in FECD point to an important etiologic component of dystrophic degeneration seen in FECD.

\section{SUMMARY AND CONCLUSION}

Fuchs endothelial corneal dystrophy is the most common dystrophic cause for corneal transplantation. The advances in surgical treatment of the disease have been astronomical, since it is possible to replace only the diseased layer of the cornea, as seen in Descemet stripping endothelial keratoplasty (DSEK) and Descemet memebrane endothelial keratoplasty (DMEK). Nevertheless, many questions remain unanswered in regards to the 
pathogenesis of the disease. The genetic basis of FECD has been further elucidated with the discovery of mutation hot-spots, linked chromosomal loci, and involved genes; however, more work is necessary to pinpoint the genes involved in common late-onset FECD. The findings in proteomic and gene expression profiles point to mitochondrial and oxidative stress-related alterations in endothelial cell ability to survive. These appear to promote an apoptotic cascade and induce endothelial cell death. Whether this is the cause or the effect of FECD is still unclear and warrants further investigation. However, a combination of environmental factors and genetic predisposition probably plays a key role in the development of FECD.

\section{ABBREVIATIONS}

8-OHdG

ABL

AGE

Bax

Bcl-2

CE

CHED

CLU

COL8A1

COL8A2

DM

DMEK

DSEK

FCD

FECD

HCEC

IC3D

ICL

NaBC1

nCLU

PBK

PBL

PFL

PNBL

PPCD

PRDX

PSL

RAGE 8-hydroxydeoxyguanosine

anterior banded layer

advanced glycation end products

Bcl-2-associated X protein

B-cell lymphoma 2

Corneal endothelium

congenital hereditary endothelial dystrophy

clusterin

collagen type VIII a1 polypeptide

collagen type VIII $\alpha 2$ polypeptide

Descemet's membrane

Descemet membrane endothelial keratoplasty

Descemet stripping endothelial keratoplasty

Fuchs corneal dystrophy locus

Fuchs endothelial corneal dystrophy

human corneal endothelial cells

International Committee for Classification of Corneal Dystrophies

internal collagenous layer

Na-borate cotransporter

nuclear clusterin

phakic bullous keratopathy

posterior banded collagenous layer

posterior fibrous layer

posterior non-banded layer

posterior polymorphous corneal dystrophy

peroxiredoxins

posterior striated layer

receptor of advanced glycation end products 


$\begin{array}{ll}\text { ROS } & \text { reactive oxygen species } \\ \text { SAGE } & \text { serial analysis of gene expression } \\ \text { SCLU } & \text { secretory clusterin } \\ \text { SLC4A11 } & \text { member } 11 \text { of solute carrier family } 4 \\ \text { TEM } & \text { transmission electron microscopy } \\ \text { TGF } \beta I p & \text { Transforming Growth Factor Induced protein } \\ \text { TUNEL } & \text { TdT-dUTP terminal nick-end labeling }\end{array}$

\section{References}

1. Fuchs E. Dystrophia epithelialis corneae. Albrecht Von Graefes Arch Klin Exp Ophthalmol. 1910; 76:478-508.

2. Iwamoto T, DeVoe AG. Electron microscopic studies on Fuchs'combined dystrophy. I. Posterior portion of the cornea. Invest Ophthalmol. 1971; 10:9-28. [PubMed: 4099043]

3. Waring GO 3rd, Rodrigues MM, Laibson PR. Corneal dystrophies. II. Endothelial dystrophies. Surv Ophthalmol. 1978; 23:147-168. [PubMed: 310583]

4. Waring, GO.; Rodrigues, MM.; Laibson, PR. Corneal dystrophies. In: Leibowitz, editor. Corneal Disorders: Clinical Diagnosis and Management. Philadelphia, PA: Saunders; 1984.

5. Weisenthal, RW.; Streeten, BW. Posterior membrane dystrophies. In: Krachmer, JH.; Mannis, MH.; Holland, EJ., editors. Cornea Volume II: Cornea and External Disease, Clinical Diagnosis and Management. St Louis, MO: Mosby-Year Book; 1997.

6. Adamis AP, Filatov V, Tripathi BJ, Tripathi RC. Fuchs' endothelial dystrophy of the cornea. Surv Ophthalmol. 1993; 38:149-168. [PubMed: 8235998]

7. Waring GO 3rd, Bourne WM, Edelhauser HF, Kenyon KR. The corneal endothelium. Normal and pathologic structure and function. Ophthalmology. 1982; 89:531-590. [PubMed: 7122038]

8. Miller, CA.; Krachmer, JH. Endothelial dystrophies. In: Kaufman, HE.; Barron, BA.; McDonald, MB.; Waltman, SR., editors. The Corneas. New York: Churchill-Livingstone; 1988.

9. Arffa, RC. Grayson's Diseases of the Cornea. St Louis, MO: Mosby-Year Book; 1991. Disorders of the endothelium.

10. Bourne, WM. Fuchs' corneal dystrophy. In: Fraunfelder, FT.; Roy, FH., editors. Current Ocular Therapy. Philadelphia, PA: Saunders; 1995.

11. Yanoff, M.; Fine, BS. Ocular Pathology. Barcelona: Mosby-Wolfe; 1996. p. 276-278.

12. Wilson SE, Bourne WM. Fuchs' dystrophy. Cornea. 1988; 7:2-18. [PubMed: 3280235]

13. Abbott RL, Fine BS, Webster RG Jr, Paglen PG, Spencer WH. Specular microscopic and histologic observations in nonguttate corneal endothelial degeneration. Ophthalmology. 1981; 88:788-800. [PubMed: 6976545]

14. Lloyd RI. Less evident causes of lowered acuity in senility. Am J Ophthalmol. 1944; 27:232-243.

15. Lorenzetti DW, Uotila MH, Parikh N, Kaufman HE. Central cornea guttata. Incidence in the general population. Am J Ophthalmol. 1967; 64:1155-1158. [PubMed: 6072991]

16. Goar EL. Dystrophy of the corneal endothelium (cornea guttata), with a report of a histological examination. Am J Ophthalmol. 1934; 17:215.

17. Kuwabara T, Quevedo AR, Cogan DG. An experimental study of dichloroethane poisoning. Arch Ophthalmol. 1968; 79:321-330. [PubMed: 5640855]

18. Kanai A, Kaufman HE. The retrocorneal ridge in syphilitic and herpetic interstitial keratitis: an electron-microscopic study. Ann Ophthalmol. 1982; 14:120-124. [PubMed: 7046592]

19. Renard G, Dhermy P, Pouliquen Y. Secondary dystrophies of corneal endothelium and Descemet's membrane: histological and ultrastructural study (author's transl). J Fr Ophtalmol. 1981; 4:721739. [PubMed: 7035536] 
20. Waring GO, Font RL, Rodrigues MM, Mulberger RD. Alterations of Descemet's membrane in interstitial keratitis. Am J Ophthalmol. 1976; 81:773-785. [PubMed: 937431]

21. Edmonds C, Iwamoto T. Electron microscopy of late interstitial keratitis. Ann Ophthalmol. 1972; 4:693-696. [PubMed: 4560392]

22. Weiss JS, Moller HU, Lisch W, et al. The IC3D classification of the corneal dystrophies. Cornea. 2008; 27 (Suppl 2):S1-83. [PubMed: 19337156]

23. Cross HE, Maumenee AE, Cantolino SJ. Inheritance of Fuchs' endothelial dystrophy. Arch Ophthalmol. 1971; 85:268-272. [PubMed: 5313141]

24. Rosenblum P, Stark WJ, Maumenee IH, Hirst LW, Maumenee AE. Hereditary Fuchs' Dystrophy. Am J Ophthalmol. 1980; 90:455-462. [PubMed: 6968504]

25. Magovern M, Beauchamp GR, McTigue JW, Fine BS, Baumiller RC. Inheritance of Fuchs' combined dystrophy. Ophthalmology. 1979; 86:1897-1923. [PubMed: 399801]

26. Krachmer JH, Purcell JJ Jr, Young CW, Bucher KD. Corneal endothelial dystrophy. A study of 64 families. Arch Ophthalmol. 1978; 96:2036-2039. [PubMed: 309758]

27. Santo RM, Yamaguchi T, Kanai A, Okisaka S, Nakajima A. Clinical and histopathologic features of corneal dystrophies in Japan. Ophthalmology. 1995; 102:557-567. [PubMed: 7724173]

28. Vithana EN, Morgan PE, Ramprasad V, et al. SLC4A11 mutations in Fuchs endothelial corneal dystrophy. Hum Mol Genet. 2008; 17:656-666. [PubMed: 18024964]

29. Becker, B.; Shafer, RN. Diagnosis and Therapy of the Glaucomas. St Louis: CV Mosby; 1976. p. 265-266.

30. Buxton JN, Preston RW, Riechers R, Guilbault N. Tonography in cornea guttata. A preliminary report. Arch Ophthalmol. 1967; 77:602-603. [PubMed: 5297860]

31. Roberts CW, Steinert RF, Thomas JV, Boruchoff SA. Endothelial guttata and facility of aqueous outflow. Cornea. 1984; 3:5-9. [PubMed: 6336058]

32. del Buey MA, Cristobal JA, Ascaso FJ, Lavilla L, Lanchares E. Biomechanical properties of the cornea in Fuchs' corneal dystrophy. Invest Ophthalmol Vis Sci. 2009; 50:3199-3202. [PubMed: 19255149]

33. Lipman RM, Rubenstein JB, Torczynski E. Keratoconus and Fuchs' corneal endothelial dystrophy in a patient and her family. Arch Ophthalmol. 1990; 108:993-994. [PubMed: 2369360]

34. Orlin SE, Raber IM, Eagle RC Jr, Scheie HG. Keratoconus associated with corneal endothelial dystrophy. Cornea. 1990; 9:299-304. [PubMed: 2078959]

35. Jurkunas U, Azar DT. Potential complications of ocular surgery in patients with coexistent keratoconus and Fuchs' endothelial dystrophy. Ophthalmology. 2006; 113:2187-2197. [PubMed: 16996603]

36. Rao GP, Kaye SB, Agius-Fernandez A. Central corneal endothelial guttae and age-related macular degeneration: is there an association? Indian J Ophthalmol. 1998; 46:145-147. [PubMed: 10085626]

37. Olsen T. Is there an association between Fuchs' endothelial dystrophy and cardiovascular disease? Graefes Arch Clin Exp Ophthalmol. 1984; 221:239-240. [PubMed: 6333375]

38. Burns RR, Bourne WM, Brubaker RF. Endothelial function in patients with cornea guttata. Invest Ophthalmol Vis Sci. 1981; 20:77-85. [PubMed: 6969713]

39. Wilson SE, Bourne WM, O'Brien PC, Brubaker RF. Endothelial function and aqueous humor flow rate in patients with Fuchs' dystrophy. Am J Ophthalmol. 1988; 106:270-278. [PubMed: 3262306]

40. Bergmanson JP, Sheldon TM, Goosey JD. Fuchs' endothelial dystrophy: a fresh look at an aging disease. Ophthalmic Physiol Opt. 1999; 19:210-222. [PubMed: 10627840]

41. McCartney MD, Wood TO, McLaughlin BJ. Moderate Fuchs' endothelial dystrophy ATPase pump site density. Invest Ophthalmol Vis Sci. 1989; 30:1560-1564. [PubMed: 2545644]

42. Klintworth GK. Corneal dystrophies. Orphanet journal of rare diseases. 2009; 4:7. [PubMed: 19236704]

43. Wulle KG. Electron microscopy of the fetal development of the corneal endothelium and Descemet's membrane of the human eye. Invest Ophthalmol. 1972; 11:897-904. [PubMed: 4634956] 
44. Murphy C, Alvarado J, Juster R. Prenatal and postnatal growth of the human Descemet's membrane. Invest Ophthalmol Vis Sci. 1984; 25:1402-1415. [PubMed: 6511224]

45. Johnson DH, Bourne WM, Campbell RJ. The ultrastructure of Descemet's membrane. I. Changes with age in normal corneas. Arch Ophthalmol. 1982; 100:1942-1947. [PubMed: 7150061]

46. Gottsch JD, Zhang C, Sundin OH, Bell WR, Stark WJ, Green WR. Fuchs corneal dystrophy: aberrant collagen distribution in an L450W mutant of the COL8A2 gene. Invest Ophthalmol Vis Sci. 2005; 46:4504-4511. [PubMed: 16303941]

47. Zhang C, Bell WR, Sundin OH, et al. Immunohistochemistry and electron microscopy of earlyonset fuchs corneal dystrophy in three cases with the same L450W COL8A2 mutation. Trans Am Ophthalmol Soc. 2006; 104:85-97. [PubMed: 17471329]

48. Bourne WM, Johnson DH, Campbell RJ. The ultrastructure of Descemet's membrane. III. Fuchs' dystrophy. Arch Ophthalmol. 1982; 100:1952-1955. [PubMed: 6983339]

49. Levy SG, Moss J, Sawada H, Dopping-Hepenstal PJ, McCartney AC. The composition of widespaced collagen in normal and diseased Descemet's membrane. Curr Eye Res. 1996; 15:45-52. [PubMed: 8631203]

50. Waring GO 3rd. Posterior collagenous layer of the cornea. Ultrastructural classification of abnormal collagenous tissue posterior to Descemet's membrane in 30 cases. Arch Ophthalmol. 1982; 100:122-134. [PubMed: 7055463]

51. Sawada H, Konomi H, Hirosawa K. Characterization of the collagen in the hexagonal lattice of Descemet's membrane: its relation to type VIII collagen. J Cell Biol. 1990; 110:219-227. [PubMed: 2104858]

52. Jakus MA. Studies on the cornea. II. The fine structure of Descement's membrane. J Biophys Biochem Cytol. 1956; 2:243-252. [PubMed: 13357549]

53. Levy SG, McCartney AC, Sawada H, Dopping-Hepenstal PJ, Alexander RA, Moss J. Descemet's membrane in the iridocorneal-endothelial syndrome: morphology and composition. Experimental eye research. 1995; 61:323-333. [PubMed: 7556496]

54. Biswas S, Munier FL, Yardley J, et al. Missense mutations in COL8A2, the gene encoding the alpha2 chain of type VIII collagen, cause two forms of corneal endothelial dystrophy. Hum Mol Genet. 2001; 10:2415-2423. [PubMed: 11689488]

55. Gottsch JD, Sundin OH, Liu SH, et al. Inheritance of a novel COL8A2 mutation defines a distinct early-onset subtype of fuchs corneal dystrophy. Invest Ophthalmol Vis Sci. 2005; 46:1934-1939. [PubMed: 15914606]

56. Mok JW, Kim HS, Joo CK. Q455V mutation in COL8A2 is associated with Fuchs' corneal dystrophy in Korean patients. Eye. 2009; 23:895-903. [PubMed: 18464802]

57. Kobayashi A, Fujiki K, Murakami A, et al. Analysis of COL8A2 gene mutation in Japanese patients with Fuchs' endothelial dystrophy and posterior polymorphous dystrophy. Jpn J Ophthalmol. 2004; 48:195-198. [PubMed: 15175909]

58. Aldave AJ, Rayner SA, Salem AK, et al. No pathogenic mutations identified in the COL8A1 and COL8A2 genes in familial Fuchs corneal dystrophy. Invest Ophthalmol Vis Sci. 2006; 47:37873790. [PubMed: 16936088]

59. Hopfer U, Fukai N, Hopfer H, et al. Targeted disruption of Col8a1 and Col8a2 genes in mice leads to anterior segment abnormalities in the eye. Faseb J. 2005; 19:1232-1244. [PubMed: 16051690]

60. Park M, Li Q, Shcheynikov N, Zeng W, Muallem S. NaBC1 is a ubiquitous electrogenic Na+coupled borate transporter essential for cellular boron homeostasis and cell growth and proliferation. Mol Cell. 2004; 16:331-341. [PubMed: 15525507]

61. Parker MD, Ourmozdi EP, Tanner MJ. Human BTR1, a new bicarbonate transporter superfamily member and human AE4 from kidney. Biochem Biophys Res Commun. 2001; 282:1103-1109. [PubMed: 11302728]

62. Vithana EN, Morgan P, Sundaresan P, et al. Mutations in sodium-borate cotransporter SLC4A11 cause recessive congenital hereditary endothelial dystrophy (CHED2). Nat Genet. 2006; 38:755757. [PubMed: 16767101]

63. Lopez IA, Rosenblatt MI, Kim C, et al. Slc4a11 gene disruption in mice: Cellular targets of sensorineuronal abnormalities. J Biol Chem. 2009 
64. Sundin OH, Jun AS, Broman KW, et al. Linkage of late-onset Fuchs corneal dystrophy to a novel locus at 13pTel-13q12.13. Invest Ophthalmol Vis Sci. 2006; 47:140-145. [PubMed: 16384955]

65. Sundin OH, Broman KW, Chang HH, Vito EC, Stark WJ, Gottsch JD. A common locus for lateonset Fuchs corneal dystrophy maps to 18q21.2-q21.32. Invest Ophthalmol Vis Sci. 2006; 47:3919-3926. [PubMed: 16936105]

66. Riazuddin SA, Eghrari AO, Al-Saif A, et al. Linkage of a mild late-onset phenotype of Fuchs Corneal Dystrophy to a novel locus at 5q33.1-q35.2. Invest Ophthalmol Vis Sci. 2009

67. Afshari NA, Li YJ, Pericak-Vance MA, Gregory S, Klintworth GK. Genome-wide linkage scan in fuchs endothelial corneal dystrophy. Invest Ophthalmol Vis Sci. 2009; 50:1093-1097. [PubMed: 18502986]

68. Borderie VM, Lopez M, Lombet A, Carvajal-Gonzalez S, Cywiner C, Laroche L. Cryopreservation and culture of human corneal keratocytes. Invest Ophthalmol Vis Sci. 1998; 39:1511-1519. [PubMed: 9660502]

69. Wilson SE, Kim WJ. Keratocyte apoptosis: implications on corneal wound healing, tissue organization, and disease. Invest Ophthalmol Vis Sci. 1998; 39:220-226. [PubMed: 9477978]

70. Bourcier T, Borderie V, Forgez P, Lombet A, Rostene W, Laroche L. In vitro effects of dexamethasone on human corneal keratocytes. Invest Ophthalmol Vis Sci. 1999; 40:1061-1070. [PubMed: 10235539]

71. Nickells RW, Zack DJ. Apoptosis in ocular disease: a molecular overview. Ophthalmic Genet. 1996; 17:145-165. [PubMed: 9010866]

72. Tempestini A, Schiavone N, Papucci L, et al. The mechanisms of apoptosis in biology and medicine: a new focus for ophthalmology. Eur J Ophthalmol. 2003; 13 (Suppl 3):S11-18. [PubMed: 12749672]

73. Borderie VM, Baudrimont M, Vallee A, Ereau TL, Gray F, Laroche L. Corneal endothelial cell apoptosis in patients with Fuchs' dystrophy. Invest Ophthalmol Vis Sci. 2000; 41:2501-2505. [PubMed: 10937560]

74. Waring, GO.; Mbekeani, JN. Corneal dystrophies. In: Leibowitz, HM.; Waring, GO., editors. Corneal Disorders: Clinical Diagnosis and Management. Philadelphia: WB Saunders; 1998. p. 227-2286.

75. Li QJ, Ashraf MF, Shen DF, et al. The role of apoptosis in the pathogenesis of Fuchs endothelial dystrophy of the cornea. Arch Ophthalmol. 2001; 119:1597-1604. [PubMed: 11709009]

76. Szentmary N, Szende B, Suveges I. P53, CD95, cathepsin and survivin pathways in Fuchs' dystrophy and pseudophakic bullous keratopathy corneas. Histol Histopathol. 2008; 23:911-916. [PubMed: 18498065]

77. Tuberville AW, Wood TO, McLaughlin BJ. Cytochrome oxidase activity of Fuchs' endothelial dystrophy. Curr Eye Res. 1986; 5:939-947. [PubMed: 3026733]

78. Jurkunas UV, Bitar M, Rawe I. Colocalization of increased transforming growth factor-betainduced protein (TGFBIp) and Clusterin in Fuchs endothelial corneal dystrophy. Invest Ophthalmol Vis Sci. 2009; 50:1129-1136. [PubMed: 19011008]

79. Jurkunas UV, Bitar MS, Rawe I, Harris DL, Colby K, Joyce NC. Increased clusterin expression in Fuchs' endothelial dystrophy. Invest Ophthalmol Vis Sci. 2008; 49:2946-2955. [PubMed: 18378577]

80. Jurkunas UV, Rawe I, Bitar MS, et al. Decreased expression of peroxiredoxins in Fuchs' endothelial dystrophy. Invest Ophthalmol Vis Sci. 2008; 49:2956-2963. [PubMed: 18378575]

81. Pucci S, Bonanno E, Pichiorri F, Angeloni C, Spagnoli LG. Modulation of different clusterin isoforms in human colon tumorigenesis. Oncogene. 2004; 23:2298-2304. [PubMed: 14755245]

82. Criswell T, Beman M, Araki S, et al. Delayed activation of insulin-like growth factor-1 receptor/ Src/MAPK/Egr-1 signaling regulates clusterin expression, a pro-survival factor. J Biol Chem. 2005; 280:14212-14221. [PubMed: 15689620]

83. Lidstrom AM, Bogdanovic N, Hesse C, Volkman I, Davidsson P, Blennow K. Clusterin (apolipoprotein $\mathrm{J}$ ) protein levels are increased in hippocampus and in frontal cortex in Alzheimer's disease. Exp Neurol. 1998; 154:511-521. [PubMed: 9878186]

84. Trougakos IP, So A, Jansen B, Gleave ME, Gonos ES. Silencing expression of the clusterin/ apolipoprotein $\mathrm{j}$ gene in human cancer cells using small interfering RNA induces spontaneous 
apoptosis, reduced growth ability, and cell sensitization to genotoxic and oxidative stress. Cancer Res. 2004; 64:1834-1842. [PubMed: 14996747]

85. Viard I, Wehrli P, Jornot L, et al. Clusterin gene expression mediates resistance to apoptotic cell death induced by heat shock and oxidative stress. J Invest Dermatol. 1999; 112:290-296. [PubMed: 10084304]

86. Yang CR, Leskov K, Hosley-Eberlein K, et al. Nuclear clusterin/XIP8, an X-ray-induced Ku70binding protein that signals cell death. Proc Natl Acad Sci U S A. 2000; 97:5907-5912. [PubMed: 10823943]

87. Reddy KB, Jin G, Karode MC, Harmony JA, Howe PH. Transforming growth factor beta (TGF beta)-induced nuclear localization of apolipoprotein J/clusterin in epithelial cells. Biochemistry. 1996; 35:6157-6163. [PubMed: 8634259]

88. Caccamo AE, Scaltriti M, Caporali A, et al. Nuclear translocation of a clusterin isoform is associated with induction of anoikis in SV40-immortalized human prostate epithelial cells. Ann N Y Acad Sci. 2003; 1010:514-519. [PubMed: 15033782]

89. Schwochau GB, Nath KA, Rosenberg ME. Clusterin protects against oxidative stress in vitro through aggregative and nonaggregative properties. Kidney Int. 1998; 53:1647-1653. [PubMed: 9607196]

90. Bates RC, Buret A, van Helden DF, Horton MA, Burns GF. Apoptosis induced by inhibition of intercellular contact. J Cell Biol. 1994; 125:403-415. [PubMed: 8163556]

91. Runager K, Enghild JJ, Klintworth GK. Focus on molecules: Transforming growth factor beta induced protein (TGFBIp). Experimental eye research. 2008; 87:298-299. [PubMed: 18291366]

92. Hashimoto K, Noshiro M, Ohno S, et al. Characterization of a cartilage-derived 66-kDa protein (RGD-CAP/beta ig-h3) that binds to collagen. Biochim Biophys Acta. 1997; 1355:303-314. [PubMed: 9061001]

93. Billings PC, Whitbeck JC, Adams CS, et al. The transforming growth factor-beta-inducible matrix protein (beta)ig-h3 interacts with fibronectin. J Biol Chem. 2002; 277:28003-28009. [PubMed: 12034705]

94. LeBaron RG, Bezverkov KI, Zimber MP, Pavelec R, Skonier J, Purchio AF. Beta IG-H3, a novel secretory protein inducible by transforming growth factor-beta, is present in normal skin and promotes the adhesion and spreading of dermal fibroblasts in vitro. J Invest Dermatol. 1995; 104:844-849. [PubMed: 7738366]

95. Kim JE, Kim SJ, Lee BH, Park RW, Kim KS, Kim IS. Identification of motifs for cell adhesion within the repeated domains of transforming growth factor-beta-induced gene, betaig-h3. J Biol Chem. 2000; 275:30907-30915. [PubMed: 10906123]

96. Watabe S, Hiroi T, Yamamoto Y, et al. SP-22 is a thioredoxin-dependent peroxide reductase in mitochondria. Eur J Biochem. 1997; 249:52-60. [PubMed: 9363753]

97. Zhang P, Liu B, Kang SW, Seo MS, Rhee SG, Obeid LM. Thioredoxin peroxidase is a novel inhibitor of apoptosis with a mechanism distinct from that of Bcl-2. J Biol Chem. 1997; 272:30615-30618. [PubMed: 9388194]

98. Kang SW, Chae HZ, Seo MS, Kim K, Baines IC, Rhee SG. Mammalian peroxiredoxin isoforms can reduce hydrogen peroxide generated in response to growth factors and tumor necrosis factoralpha. J Biol Chem. 1998; 273:6297-6302. [PubMed: 9497357]

99. Krapfenbauer K, Engidawork E, Cairns N, Fountoulakis M, Lubec G. Aberrant expression of peroxiredoxin subtypes in neurodegenerative disorders. Brain Res. 2003; 967:152-160. [PubMed: 12650976]

100. Kim SH, Fountoulakis M, Cairns N, Lubec G. Protein levels of human peroxiredoxin subtypes in brains of patients with Alzheimer's disease and Down syndrome. J Neural Transm Suppl. 2001:223-235. [PubMed: 11771746]

101. Chae HZ, Robison K, Poole LB, Church G, Storz G, Rhee SG. Cloning and sequencing of thiolspecific antioxidant from mammalian brain: alkyl hydroperoxide reductase and thiol-specific antioxidant define a large family of antioxidant enzymes. Proc Natl Acad Sci U S A. 1994; 91:7017-7021. [PubMed: 8041738] 
102. Zhou Y, Kok KH, Chun AC, et al. Mouse peroxiredoxin V is a thioredoxin peroxidase that inhibits p53-induced apoptosis. Biochem Biophys Res Commun. 2000; 268:921-927. [PubMed: 10679306]

103. Chae HZ, Kim IH, Kim K, Rhee SG. Cloning, sequencing, and mutation of thiol-specific antioxidant gene of Saccharomyces cerevisiae. J Biol Chem. 1993; 268:16815-16821. [PubMed: 8344960]

104. Buddi R, Lin B, Atilano SR, Zorapapel NC, Kenney MC, Brown DJ. Evidence of oxidative stress in human corneal diseases. J Histochem Cytochem. 2002; 50:341-351. [PubMed: 11850437]

105. Wang Z, Handa JT, Green WR, Stark WJ, Weinberg RS, Jun AS. Advanced glycation end products and receptors in Fuchs' dystrophy corneas undergoing Descemet's stripping with endothelial keratoplasty. Ophthalmology. 2007; 114:1453-1460. [PubMed: 17320180]

106. Bitar MS, Jurkunas UV. Antioxidant Gene Profiling and Oxidative DNA Damage in Fuchs Endothelial Corneal Dystrophy. Invest Ophthalmol Vis Sci. 2009:50. E-Abstract 3889.

107. Johns DR. Seminars in medicine of the Beth Israel Hospital, Boston. Mitochondrial DNA and disease. N Engl J Med. 1995; 333:638-644. [PubMed: 7637726]

108. Online Mendelian Inheritance in Man, OMIM (TM). McKusick-Nathans Institute of Genetic Medicine, Johns Hopkins University; Baltimore, MD: National Center for Biotechnology Information, National Library of Medicine; Bethesda, MD: $\{6 / 15 / 2009\}$. World Wide Web URL: http://www.ncbi.nlm.nih.gov/omim/ 


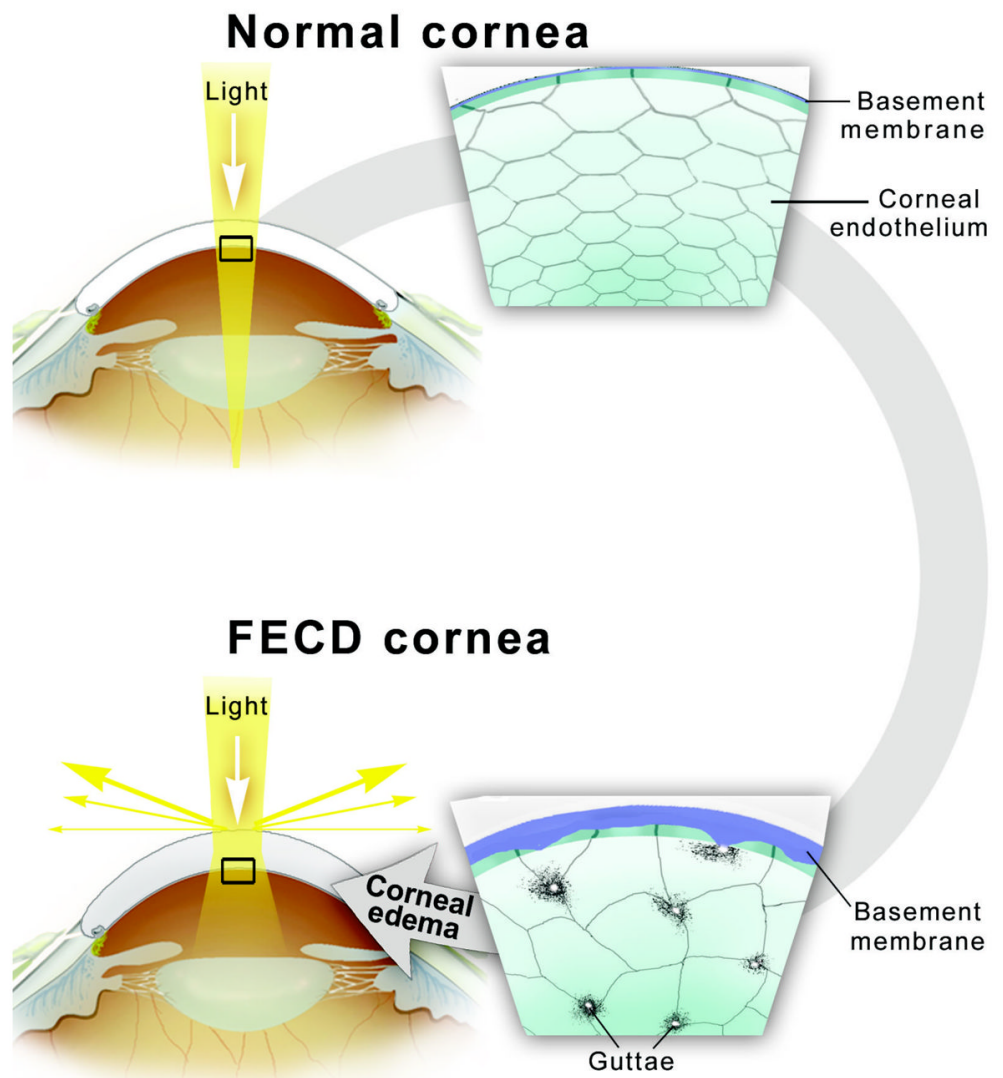

Figure 1.

Pathogenesis of FECD. Genetic and environmental factors lead to corneal endothelial cell loss, resulting in corneal edema and blurring of vision. Some characteristic histological findings are endothelial cell morphological changes, thickened Descemet's membrane, and guttae formation. 


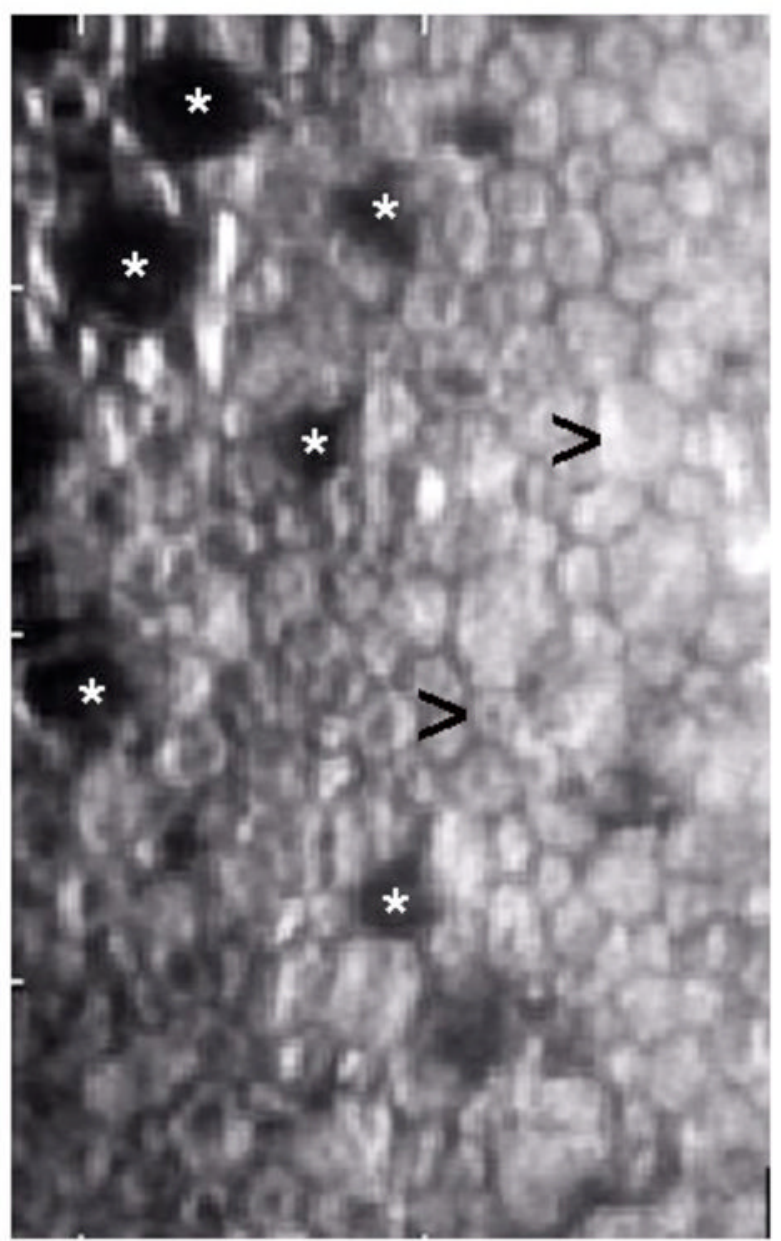

Figure 2.

Specular microscopy of a patient with FECD. Arrowheads point to the variability observed in corneal endothelial cell size (polymegathism) and shape (pleomorphism). Stars represent guttae. 


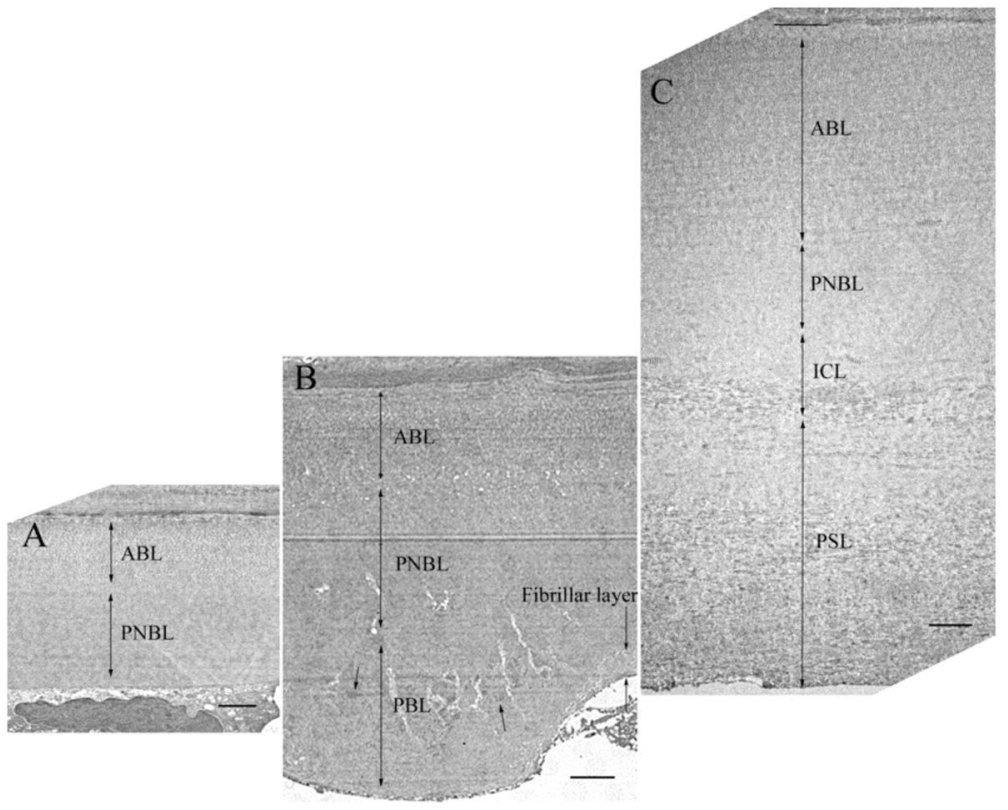

Figure 3.

Ultrastructure of Descemet's membrane of a normal cornea (A), and late-onset (B) and early-onset (C) FECD. Scale bar: $2 \mu \mathrm{m}$. (Reprinted with permission from Gottsch JD, et al. 46) 


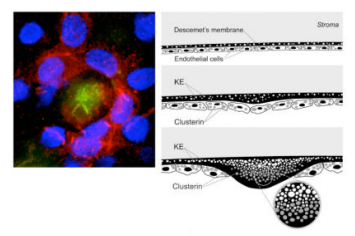

Figure 4.

Colocalization of clusterin (red) and TGFßIp (green) in FECD-affected endothelium. Endothelial cell nuclei (blue) cluster around a gutta (A). Schematic representation of guttae formation and gradual accumulation of clusterin (CLU) and TGF $\beta$ Ip or keratoepithelin (KE) in Descemet's membrane (B). 
